\title{
Removal of Stone Cells From Guava Nectar
}

\author{
F. Sanchez Nieva, A. J. Rodriguez, ${ }^{1}$ and M. A. Gonzalez ${ }^{2}$
}

\section{INTRODUCTION}

Guava nectar is the product prepared by diluting with water to desired consistency the juice and pulp of the fruit, packed with the addition of sugar and other sweetening ingredients and fruit acids, stabilizers, and artificial color, when needed to improve the flavor and appearance. The pulp and juice are extracted by comminuting the whole fruit and separating $(1)^{3}$ the seed from the edible portion in a paddle-pulper. The pulp is treated in a paddle-finisher provided with a fine screen usually with perforations 0.020 inch in diameter. If this pulp is used without any further treatment to prepare the nectar, the product has the undesirable characteristic of feeling gritty in the mouth and throat. This is because of the presence in the nectar of gritty particles known as "stone cells."

Stone cells are found in the outer flesh or rind of the guava. Some guava varieties contain more stone cells than others. Stone cells separated from guava nectar prepared from local varieties were analyzed by Santini and Nadal (2) and found to have the following chemical composition:

\begin{tabular}{lc}
\multicolumn{2}{c}{$\begin{array}{c}\text { Chemical Composition of Stone Cells } \\
\text { Component }\end{array}$} \\
Fat & 0.92 \\
Ash & 1.05 \\
Protein $(\mathrm{N} \times 6.25)$ & 1.50 \\
Lignin & 37.12 \\
Cellulose & 53.92 \\
Soluble carbohydrates & 5.49
\end{tabular}

Since stone cells consist mostly of undigestible matter they can be removed from the nectar without any effect on flavor or nutritive value. The grittiness may also be reduced by disintegrating the stone cells so that the size of the particles remaining in the nectar is such that their presence is no longer objectionable.

This paper summarizes the results of experiments conducted at the Food Technology Laboratory of this Agricultural Experiment Station with the

1 Technical Director and Chemical Engineer, respectively, Food Technology Laboratory, Agricultural Experiment Station, University of Puerto Rico, Río Piedras, P.R.

2Assistant Chemical Engineer (1958-1962), Food Technology Laboratory, Agrioultural Experiment Station, University of Puerto Rico, Río Piedras, P.R. Present address: Commonwealth of Puerto Rico, Water Resources Authority, San Juan, P.R.

Italic numbers in parentheses refer to Literature Cited, p. 243. 
objectives of improving the quality of guava nectar by lowering the grittiness, either through the physical removal of the particles from the nectar or by the reduction of the size of the stone-cell particles.

\section{MATERIALS AND METHODS}

\section{PROCESSING}

The guavas (Psidium guajava L) used in this study came from two sources: Cultivated selections from the Agricultural Experiment Station farms and seedling guavas from local farmers. Since for the purposes of these studies the type of guava used was of secondary importance, one or the other type was used as available, and either processed separately or mixed.

In the early part of the work, the nectar was prepared as described by Sánchez-Nieva (1). The fruit was dispersed in water by means of a highspeed blendor using 80 pounds of water for every 100 pounds of fruit processed. The fruit dispersion was pumped to a paddle-pulper provided with a screen with perforations 0.045 inch in diameter. After separation of the seed, the puree was treated in a paddle-finisher with a 0.020 -inch screen. In later experiments the fruit was comminuted in a Fitzmill comminuting machine, the comminuted fruit dropping by gravity to the paddlepulper. The pulp was pumped to a finisher provided with a 0.020 -inch screen.

After finishing, the pulp was diluted with water to a predetermined viscosity, which was in the range of 30 to 32 seconds when measured as described under Analytical Methods. The diluted puree was centrifuged in a solid bowl centrifugal with the 12-inch-diameter bowl spinning at 2,100 r.p.m. The centrifuged nectar was standardized by adding sugar to $15^{\circ} \mathrm{Brix}$, and acid to lower the $\mathrm{pH}$ to 3.7 when needed. FDC red No. 2 color was added when yellow-flesh varieties were used; no artificial color was added when pink-flesh fruit was processed.

The nectars were pasteurized at $190^{\circ} \mathrm{F}$. and filled while hot into fully enameled cans with a side-seam stripe and, after closing, the cans were rapidly cooled to $100^{\circ} \mathrm{F}$. in a spinner-cooler. The cans were stored until used at $85^{\circ} \mathrm{F}$.

When the stone mill was used to reduce the grittiness, the pulp from the finisher was pumped directly without dilution to the stone mill. The mill was adjusted to a clearance between stones of 0.002 inch. No. 5100 stones (fine grit) were used.

The stone-mill-treated pulp was diluted to nectar consistency using viscosity to control dilution. Addition of sugar, fruit-acid, color, packaging, and storage proceeded as previously indicated. 


\section{ANALYTICAL METHODS}

The pulp content of the nectars was determined by centrifugation of a $50-\mathrm{ml}$. sample in a 50-ml. graduated tube in a laboratory centrifugal operated at 1,500 r.p.m. The volume occupied by the pulp after centrifugation of the sample for 3 minutes was taken as a measure of the pulp content.

The stone-cell content was determined by centrifugation of a $50-\mathrm{ml}$. sample of a nectar in the same way as described above, but operating the centrifugal at 3,000 r.p.m. for 5 minutes. The stone cells collected on the bottom of the conical centrifuge tube and the volume occupied was taken as a measure of the stone-cell content.

Viscosity measurements were carried out with a viscometer constructed in the laboratory consisting of a copper tube 1 foot long and 1.25 inches in diameter, provided with an orifice 0.070 of an inch in diameter. One hundred fifty milliliters of pulp dispersion or nectar were poured into the tube and the time required for $100 \mathrm{ml}$. to flow through the orifice was taken as a measure of viscosity. Viscosity measurements were made at $85^{\circ} \mathrm{F}$. and the results are expressed in seconds.

Vitamin $\mathrm{C}$ determinations were made by the method of Ballantine (8).

The particle-size distribution in the uncentrifuged nectar in the solids retained in the centrifuge and in the centrifuged nectar were determined as follows: $250 \mathrm{ml}$. of the material were diluted with water to a final volume of $500 \mathrm{ml}$. The solids were separated from the liquid portion in Nos. 40,60, 80 , and 100 standard sieves. When all the liquid went through a screen, the solids were washed for 1 minute with distilled water and drained for 5 minutes before weighing. Size distribution is expressed as the percentage of solids retained on the screen in terms of total solids retained on all screens.

\section{RESULTS AND DISCUSSION}

\section{REMOVAL OF STONE CELLS FROM THE NECTAR}

In the early part of our studies we attempted to remove the stone cells from the nectar by filtration. The filter clogged rapidly even when 30 -mesh screens were used, and if coarser screens were used, the stone cells were not removed.

Attempts were then made to remove the stone cells by centrifugation. For this purpose, a solid-basket centrifugal with a 12-inch-diameter bowl spinning at 2,100 r.p.m. was used. The pulp from the finisher was diluted with water to a predetermined viscosity and centrifuged at the rate of 3 to 3.5 gal. per min. When samples of the centrifuged nectar were submitted to quality appraisal, using uncentrifuged samples as controls, tasters indicated their preference for the centrifuged samples. From a series of 
organoleptic tests conducted with nectars containing several levels of grittiness, it was found that a stone-cell content of about 4 to 6 percent was acceptable. Nectars with higher stone-cell content were found gritty and those with very low stone-cell content were found flat in flavor and somewhat lacking the typical flavor of the fresh fruit.

Since the percentage removal of stone cells from the nectar depends not only on the original content in the untreated sample, but also on the length of the centrifugation cycle, a series of tests was conducted in which batches were centrifuged while taking samples at frequent intervals to determine the packed-solids and stone-cell content. The data obtained from this experiment are given in table 1 . The data show that during the early part of the cycle, when only one-fourth of the batch had been centrifuged, almost all of the stone cells had been removed together with some of the coarser pulp. Later in the cycle the stone-cell content gradually increased

TABLE 1.-Variations in packed solids and stone-cell content of guava nectar (percent by volume) during centrifugation of a 40-gallon batch at a rate of $3.1-8.5$ g.p.m.

\begin{tabular}{c|c|c|c|c}
\hline \multirow{2}{*}{$\begin{array}{c}\text { Portion of batch } \\
\text { centrifuged }\end{array}$} & \multicolumn{2}{|c|}{ Packed solids } & \multicolumn{2}{c}{ Stone-cell content } \\
\cline { 2 - 5 } & Range & Mean & Range & Mean \\
\hline 0 & $61.0-74.0$ & 64.2 & $10.0-12.0$ & 10.7 \\
$1 / 4$ & $70.0-90.0$ & 80.0 & $0-0.4$ & .1 \\
$1 / 2$ & $53.0-62.0$ & 59.0 & $1.0-4.0$ & 2.5 \\
$3 / 4$ & $53.0-70.0$ & 61.5 & $4.0-9.0$ & 6.0 \\
All & $56.0-64.0$ & 59.3 & $4.0-6.0$ & 5.5 \\
\hline
\end{tabular}

and when 40 gallons had been centrifuged, the stone-cell content was around 5 to 6 percent, which is the maximum that can be allowed in the nectars, as indicated earlier.

The reduction in the packed-solid content which takes place during centrifugation is nearly equivalent to the percentage of stone cells removed.

When the solid-basket centrifugal was operated under the conditions indicated, in which the volume of the batches centrifuged was 40 gallons, and the rate of feed to the centrifuge around 3.0 to 3.5 gallons per minute, 0.51 pound of solids per gallon of nectar centrifuged were removed, which is equivalent to 13.4 pounds of solids per 100 pounds of fruit processed. The centrifuged solids occupied a volume of 0.06 gallon. Disregarding other losses, centrifugation resulted in lowering the yield of nectar by 1.6 gallons for every 100 pounds of fruit processed.

The effect of centrifugation on the particle-size distribution of the suspended pulp is shown in figure 1. Centrifugation has the effect of lowering the content of solids retained in a No. 40 screen $(35 \mathrm{mesh})$, which apparently 
are the solids causing the grittiness. The 35-mesh solids are concentrated on the solids separated in the centrifugal bowl. Centrifugation also removed a small percentage of pulp, as evidenced by the presence of $60-, 80-$, and 100-mesh solids in these centrifuged solids.

The solid-basket centrifuge has the disadvantage that the percentage of stone-cell removal depends on the length of the cycle, and that the centrifuge must be stopped for cleaning the bowl at frequent intervals. Seeking a continuous method for removing the stone cells, the Dorr-Clone cyclone separator was used. As the feed stream spirals down the cone in the sepa-

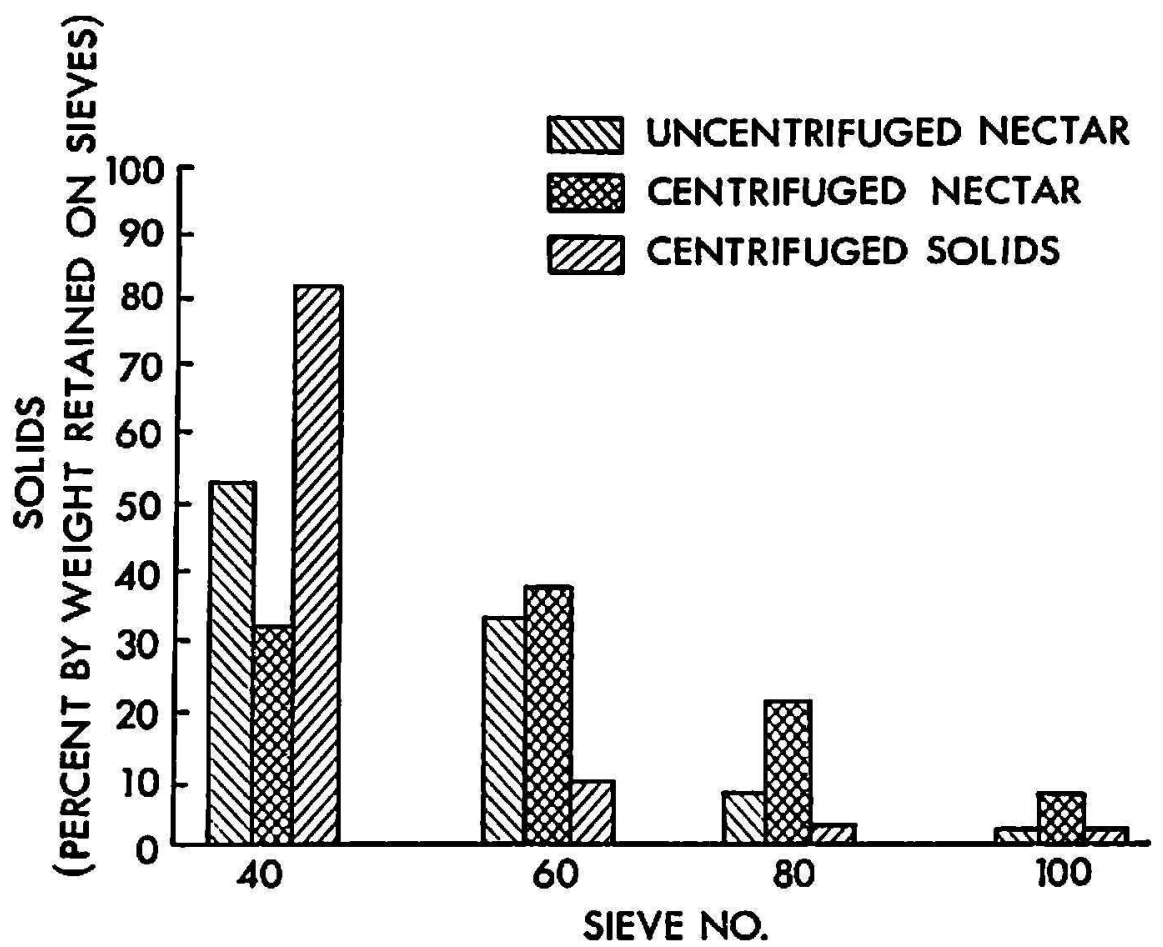

FIg. 1.-Particle-size distribution in uncentrifuged and centrifuged guava nectar 8 and in centrifuged solids.

rator, oversize particles are thrown to the wall by centrifugal force. This oversize material is carried to the apex of the cone and discharges continuously from the separator. The main body of the liquid spirals upward in the inner vortex and discharges through the upper port and then out through the overflow connection.

Although it was possible to remove the stone cells from guava nectar by the use of the cyclone separator to nearly the same level as with the solidbasket centrifuge, a higher percentage of solids was removed, resulting in much higher losses than in centrifugation. Although only a limited number of tests was conducted with the cyclone separator; the lower yields of nectar obtained when using this method for removing the stone cells discouraged further investigations. 


\section{SIZE REDUCTION OF STONE-CELL PARTICLES}

\section{PROCEDURES}

A second series of experiments was conducted with the objective of eliminating the effect of the stone cells on palatability by disintegrating the stone cells. In these experiments the methods investigated were directly compared with the centrifugal separation.

A number of tests were conducted in which nectars preparcd as already described were treated in a colloid mill consisting of grooved conical rotor rotating with a correspondingly grooved conical stator. The nectar was pumped through the colloid mill with the cones adjusted at different clearances. The treated nectars were compared organoleptically for stonecell content with their centrifuged counterparts. Even when the cones were adjusted to a clearance of 0.006 inch, the centrifuged nectars were found to contain much fewer stone cells.

Another method of reducing the grittiness is the treatment of the pulp in a mustard mill. This method has been used commercially in Hawaii (4). A number of experiments were conducted using a Morehouse Series 500 stone mill with a water jacket to reduce overheating of the product.

Nectar was prepared by comminuting the fruit, pulping in a paddlepulper with 0.045-inch screens, finishing the pulp in a paddle-finisher with 0.020 -inch screens. The puree was divided in two parts. One part was diluted to nectar consistency and centrifuged in the solid-bowl centrifugal, as previously described. The other portion was treated without dilution in the stone mill and then diluted to nectar consistency.

Nectars were canned, adding sugar, fruit acid, and color whenever necessary. In all these tests the stone mill was operated with fine-grit (No. 5100 Morehouse) stones with a clearance of around 0.002 inch, as exploratory tests previously conducted showed that under these conditions the mill operated more efficiently in disintegrating the stone cells.

\section{ORGANOLEPTIC TESTS}

The nectar prepared by centrifugation and by treatment in the stone mill was submitted to quality appraisal to experienced judges working under red light. Two types of tests were conducted. The nectars were compared with each other using the pair test. Tasters were asked to indicate their preference for one of the samples and to select the sample having the most pleasing flavor and stronger guava flavor. These tests were conducted with samples which were stored at $85^{\circ} \mathrm{F}$. for $42,75,134,163$, and 257 days.

The results of these tests are given in table 2. These show that tasters could not differentiate between centrifuged and stone-mill-treated samples in any of three quality attributes tested, except for one pair of samples 
tested after 134 days of storage at $85^{\circ} \mathrm{F}$. For these two samples, tasters found the centrifuged nectar better in quality and in flavor, the difference between samples being significant at the 5-percent probability level. It should be noted that, although no statistical difference could be found be-

TABLE 2.-Results of the organoleptic comparisons by the pair test of guava nectars with the grittiness removed by centrifugation and by treatment in the stone mill

\begin{tabular}{|c|c|c|c|c|c|c|c|c|c|c|c|}
\hline \multirow{3}{*}{$\begin{array}{c}\text { Characteristic } \\
\text { measured }\end{array}$} & \multirow{3}{*}{$\begin{array}{l}\text { Sample } \\
\text { No. }\end{array}$} & \multicolumn{10}{|c|}{$\begin{array}{l}\text { Percentage of tasters selecting the sample after storage at } 85^{\circ} \mathrm{F} \text {. } \\
\text { for the number of days indicated }\end{array}$} \\
\hline & & \multicolumn{2}{|c|}{42} & \multicolumn{2}{|c|}{75} & \multicolumn{2}{|c|}{134} & \multicolumn{2}{|c|}{163} & \multicolumn{2}{|c|}{257} \\
\hline & & c & SM & c & SM & c & SM & C & SM & c & SM \\
\hline \multirow[t]{3}{*}{ Preference } & 1 & 60 & 40 & 75 & 25 & 54.2 & 45.8 & 60 & 40 & 78 & 22 \\
\hline & 2 & 85 & 15 & - & - & 90.0 & 10.0 & 75 & 25 & 75 & 25 \\
\hline & 3 & 64 & 36 & - & - & 33.0 & 67.0 & 60 & 40 & 75 & 25 \\
\hline \multirow[t]{3}{*}{ Better flavor } & 1 & 70 & 30 & 75 & 25 & 54.0 & 46.0 & 60 & 40 & 78 & 22 \\
\hline & 2 & 77 & 23 & - & - & 90.0 & 10.0 & 85 & 15 & 60 & 40 \\
\hline & 3 & 64 & 36 & - & - & 67.0 & 33.0 & 60 & 40 & 75 & 25 \\
\hline \multirow{3}{*}{$\begin{array}{l}\text { Strongest guava } \\
\text { flavor }\end{array}$} & 1 & 50 & 50 & 70 & 30 & 55.0 & 45.0 & 60 & 40 & 77 & 23 \\
\hline & 2 & 69 & 31 & - & - & 85.0 & 15.0 & 80 & 20 & 70 & 30 \\
\hline & 3 & 50 & 50 & - & - & 55.0 & 45.0 & 60 & 40 & 70 & 30 \\
\hline
\end{tabular}

${ }^{1} \mathrm{C}$, Centrifuged nectars; SM, nectars treated in the stone mill.

TABLE 3.-Results of the organoleptic appraisal, using a 9-point hedonic scale, of guava nectars with the grittiness removed by centrifugation and by treatment in the stone mill

\begin{tabular}{c|c|c}
\hline \multirow{2}{*}{ Sample No. } & \multicolumn{2}{|c}{ Hedonic-scale values for the nectar prepared as indicated } \\
\cline { 2 - 3 } & Centrifuged & Stone mill \\
\hline 1 & 7.3 & 7.0 \\
2 & 7.3 & 7.7 \\
3 & 7.3 & 7.3 \\
4 & 7.4 & 7.0 \\
\hline
\end{tabular}

tween the samples throughout the storage period of 328 days, there was a trend for a higher percentage of tasters to prefer the centrifuged nectar.

In the other series of tests, the nectars were submitted to the judges separately and a 9-point hedonic scale ranging from dislike extremely to like extremely was used for evaluating the samples. The results obtained for four groups of nectars submitted to taste tests are given in table 3 . They show that tasters could not differentiate between samples, rating both essentially alike. 
The results of this test show it is possible to reduce the stone-cell content of guava nectar, using the stone mill, to nearly the same level as that obtained by the centrifugation process. Nectars prepared by both procedures were similar in quality being equally accepted by tasters. Both types had almost the same shelf-life.

Since it is possible to prepare nectars of similar quality and degree of acceptance by removing the stone cells by centrifugation or by disintegrating the stone-cell aggregates, the choice of the method to be used commercially rests on the yields to be obtained from each.

When a number of nectars were prepared on pilot-plant scale, one group being centrifuged and the other treated in the stone mill, the yields of nectar obtained in gallons per 100 pounds of fruit processed, are given in the following tabulation:

\begin{tabular}{|c|c|}
\hline \multicolumn{2}{|c|}{$\begin{array}{l}\text { Effect of treatment on yields: } \\
\text { oblained from } 100 \mathrm{lb} \text {. of fruit processed when the }\end{array}$} \\
\hline Cenlrifugation & Stone-mill treatment \\
\hline $\begin{array}{l}26.18 \\
30.92 \\
26.42 \\
27.57 \\
26.50 \\
30.50 \\
32.35\end{array}$ & $\begin{array}{l}27.38 \\
31.35 \\
28.96 \\
28.43 \\
28.70 \\
34.14 \\
33.60\end{array}$ \\
\hline Average 28.63 & 30.36 \\
\hline
\end{tabular}

These results show that treatment of the nectars in the stone mill produce higher yields. The higher yields of nectar obtained by this method occur not only because the stone cells are not removed, but because the stone mill has an almost negligible holdup as compared with the solid-bowl centrifugal. In use the stone mill proved to be superior to the solid-bowl centrifuge from the standpoint of yields. The use of the stone mill offers the additional advantage that the batch operation characteristic of solidbasket centrifugation is avoided, and the nectars can be produced by a continuous process.

The stone mill, however, was found to have an adverse effect on the color of pink-colored guavas, and on the vitamin $\mathrm{C}$ content. Since the outer flesh where the stone cells are mostly concentrated is yellow, even in pink and reddish varieties, disintegration of this layer and its incorporation into the nectar results in a more yellowish color. Since most of this layer is removed by centrifugation, the nectars have a brighter reddish color. The 
effect of both treatments on the color of nectars prepared from pink-fleshed fruit is shown in figure 2. This figure shows the values of $\tan ^{-1} a / b$ for both types of samples, the centrifuged and the stone-mill-treated when $a$ and $b$ values were measured in Hunter Color and Color Difference Meter. A decrease in the value of $\tan ^{-1} a / b$ indicates $(\sigma)$ a loss of the red color of the product.

Nectars prepared from pulp treated in the stone mill were found to have a much lower vitamin $\mathbf{C}$ content than centrifuged nectar. A study of the loss of vitamin $\mathbf{C}$ content during centrifugation and treatment in the stone mill shows that 22.5 percent of the vitamin $\mathrm{C}$ in the pulp is lost during the

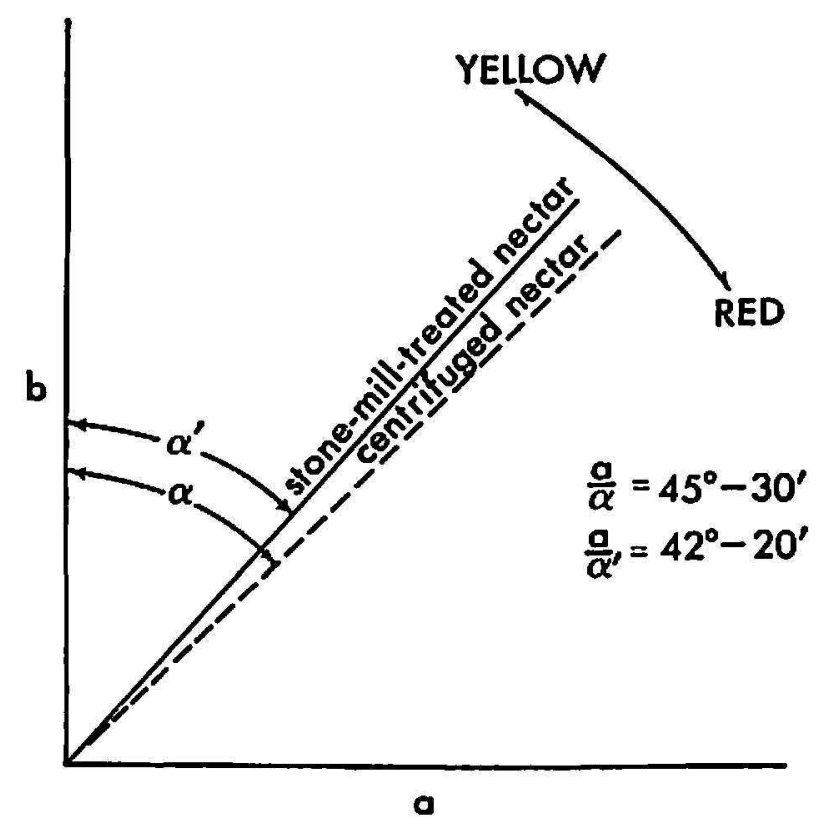

Fia. 2.-Effect of the treatment used to remove the grittiness of guava nectar on the color of the finished product when processing pink-fleshed varieties.

treatment in the stone mill, while the loss of vitamin $\mathrm{C}$ by the nectar during centrifugation is negligible. The vitamin $\mathrm{C}$ content of the pulps and nectars before and after the treatments to reduce the grittiness are given in the following tabulation:

\section{Matcrial}

Pulp from finisher

Pulp after treatment in the stone mill

Diluted pulp before centrifugation

Diluted pulp after centrifugation

Nectar prepared from stone-mill-treated pulp

Centrifuged nectar $\underset{(m g . / 100 \mathrm{gm} .)}{\operatorname{Vitamin} C}$

65.76

50.85

17.02

18.01

4.49

11.76

The higher loss of vitamin $\mathrm{C}$ during treatment of the pulp in the stone 
mill was attributed to an increase in the temperature of the pulp of around $7-10^{\circ} \mathrm{F}$. in passage through the mill.

\section{SUMMARY}

Several methods have been investigated for reducing the grittiness of guava nectar caused by the presence of stone cells. Of the several methods tried, which included filtration, centrifugation, cyclone separation, and particle-size reduction using a colloid mill and a stone mill, centrifugation and treatment in the stone mill proved to be the best. When the nectars are centrifuged in a solid-basket centrifugal, the grittiness was completely eliminated, since the stone cells responsible for this grittiness are separated during the process. Nectars of similar quality were prepared by size reduction of the stone-cell particles in a stone or mustard mill.

A comparison of both methods showed that higher yields of nectar are obtained when the stone mill is used to disintegrate the stone cell, but some discoloration results when pink-colored fruit is treated thus. Treatment in the stone mill also results in a higher loss of vitamin $\mathrm{C}$ when compared to the loss that results when the nectars are centrifuged.

\section{RESUMEN}

Se estudiaron varios métodos para eliminar o disminuir la granosidad del néctar de guayaba. De los distintos métodos probados, es decir, el de filtración, centrifugación, separación en un separador ciclónico y reducción en el tamaño de las partículas mediante un molino de coloides y uno de piedra, la centrifugación y el del molino de piedra fueron los mejores. Mediante ambos procedimientos fue posible preparar néctares de excelente calidad, cuya granosidad era aceptable.

Usando el molino de piedra se obtuvieron más altos rendimientos de néctar, aunque este método afectó adversamente el color de la pulpa extraída de frutas de pulpa rosada, causando, además, una pérdida mayor del contenido de vitamina $\mathrm{C}$ en el producto elaborado.

\section{LITERATURE CITED}

1. Sánchez-Nieva, F., Nuevos procedimientos para la elaboración de los néctares de mango, guayaba y guanábana, Misc. Pub. 6, Agr. Expt. Sta., Univ. P.R., July 1952.

2. Santini, R. Jr., and Nadal, N., Chemical analysis of the stone cells present in guava, J. Agr. Univ. P.R. $39(3): 172,1955$.

3. Ballantine, R., Determination of ascorbic acid in citrus fruit juices, Ind. Eng. Chem. Anal. ed. 18: 89, 1941.

4. Boyle, F. P., Seagrave-Smith, H., Sakata, S., and Sherman, D. G., Commercial guava processing in Hawaii, B. 111, Hawaii Agr. Expt. Sta., Univ. Hawaii, June 1957.

5. Francis, F. J., A method of measuring the skin color of apples, Proc. Amer. Soc. Hort. Sci. 60: 213-20, 1952. 